\title{
The impact of frequency, pattern, intensity, and type of alcohol consumption, and its combined effect with smoking on inflammation, lipid profile, and the risk of myocardial infarction
}

\author{
Ritienne Attard ${ }^{1}$ - Philip Dingli ${ }^{1}$ - Carine J. M. Doggen ${ }^{2} \cdot$ Karen Cassar $^{3} \cdot$ Rosienne Farrugia $^{1}$. \\ Stephanie Bezzina Wettinger ${ }^{1}$ (ID
}

Received: 23 July 2019 / Accepted: 20 November 2019 / Published online: 14 December 2019

(C) The Author(s) 2019

\begin{abstract}
Aim To determine the risk of myocardial infarction (MI) associated with pattern, frequency, and intensity of alcohol consumption, type of alcoholic beverage, and the combined effect of alcohol and smoking on risk of MI, inflammation, and lipid profile. Method A total of 423 cases with a first MI and 465 controls from the Maltese Acute Myocardial Infarction (MAMI) Study were analysed. Data was collected through an extensive interviewer-led questionnaire, along with measurements of various blood parameters. Medians and the Mann-Whitney test were used to assess effect of different drinking patterns, frequency, intensity, and smoking and drinking combinations on hs-CRP and lipid profile. Odds ratios, adjusted for the conventional risk factors of MI (AdjORs), were calculated as an estimate of the relative risk of MI.

Results Regular alcohol consumption protected against MI [AdjOR 0.6 (95\% CI 0.4-0.9)] while daily binge drinking increased risk [AdjOR 5.0 (95\% CI 1.6-15.0)] relative to regular drinkers who did not binge drink. Whereas moderate weekly consumption of wine protected against MI, high weekly consumption of beer conveyed a deleterious effect. Alcohol consumption decreased risk of MI independent of smoking status. Frequent alcohol consumption was associated with higher HDL-, non-HDL-, total cholesterol and triglycerides, and lower hs-CRP. Total and HDL-cholesterol increased and BMI decreased with increasing quantity of weekly alcohol consumption relative to the non-regular drinkers. The effect of smoking on lipid profile and hsCRP was less pronounced in current drinkers than in those who were non-regular drinkers.

Conclusion The protective effect of alcohol consumption was dependent on the pattern, frequency, type, and intensity of alcohol consumed. Alcohol modified the effects of smoking on the lipid profile. Regular drinking attenuated the effect of smoking on hsCRP and lipid profile.
\end{abstract}

Keywords Alcohol consumption $\cdot$ Myocardial infarction $\cdot$ Inflammation $\cdot$ Lipid profile

Electronic supplementary material The online version of this article (https://doi.org/10.1007/s10389-019-01172-3) contains supplementary material, which is available to authorized users.

Stephanie Bezzina Wettinger

stephanie.bezzina-wettinger@um.edu.mt

1 Department of Applied Biomedical Science, Faculty of Health Sciences, University of Malta, MSD2080 Msida, Malta

2 Health Technology and Services Research, MIRA, University of Twente, Enschede, The Netherlands

3 Faculty of Medicine and Surgery, University of Malta, Msida, Malta

\section{Introduction}

Low to moderate alcohol consumption has been associated with a decreased risk of coronary artery disease and acute myocardial infarction (MI) (Romelsjo et al. 2012; Ronksley 2011), while heavy alcohol consumption and binge drinking promote atherogenesis (Keichl et al. 1998; Leong et al. 2014). The opposing effects that different drinking patterns exert on the risk of MI are partly due to their different physiological effects on lipid metabolism (McKee and Britton 1998). While studies on the role of alcohol consumption in various conditions are numerous, less is known about its effect on the risk of MI when found in combination with other conventional risk factors of MI, such as smoking (Tavani et al. 2001) and their combined influence on inflammation and lipid profile 
(Wakabayashi 2008; Liu et al. 2018). Conflicting literature on the effect of moderate alcohol intake on the lipid profile $(\mathrm{Vu}$ et al. 2016; Ruidavets et al. 2002; Van de Wiel 2011; Park and Kim 2012) may be due to failure to account for the drinking pattern, the type of alcoholic beverage consumed, and the presence of other risk factors such as smoking, which often occurs with drinking (Grucza and Bierut 2006). More so since alcohol consumption and smoking may have opposite effects on the lipid profile and thus on atherogenicity (Wakabayashi 2008). The combined effect of these common risk factors on the inflammatory state and lipid profile may shed light on the mechanism/s through which they influence the risk of MI.

The Maltese Acute Myocardial Infarction (MAMI) Study is a case-control study in the Maltese population. The influence of different patterns (binge drinking), types of alcoholic beverages, frequency, and intensity (drinking units) of alcohol consumption on the risk of MI was investigated as part of this study, together with their effect on inflammation and the lipid profile. Given that smoking often accompanies alcohol consumption the combined effect of these lifestyle factors on inflammation, lipid profile, and the risk of MI was also assessed.

\section{Methods}

\section{Study design}

MI was defined according to the guidelines issued by the Joint European Society of Cardiology/American College of Cardiology committee (Alpert et al. 2000). Research subjects included 423 consecutive cases admitted with a first MI, to Mater Dei Hospital or Gozo General Hospital, Malta, between June 2011 and April 2013, and 465 population controls, all of Maltese descent (Attard et al. 2017). The maximum age of cases was 70 years for men and 75 years for women. Cases were reviewed twice during the study, once at the time of hospital admission and at least 6 months later at a follow-up visit. Controls were recruited from the general population through a random list of addresses generated by the National Statistics office. A postal invitation was sent followed by a telephone invitation. An electrocardiogram (ECG) was performed on all research subjects. Controls with a history of MI, percutaneous coronary intervention, coronary bypass surgery, or ECG evidence of a previous or silent MI or of left bundle branch block were excluded from the study. The control group was frequency-matched to cases on gender and 10year age groups.

\section{Data collection}

Data on the conventional risk factors for MI, including age, gender, smoking, alcohol consumption, diabetes mellitus, hypertension, hypercholesterolemia, and other potential risk factors were collected through several sources. These included an extensive interviewer-led questionnaire, list of medications, physical measurements, including blood pressure, weight and height, and various biochemical tests including $\mathrm{HbAlc}$, high sensitivity C-reactive protein (hs-CRP) levels, lipid profile, liver function tests, and renal profile. Questionnaire data for cases was at time of hospital admission with MI. Data on 29 cases was not available and so these were excluded from the analyses. Body mass index (BMI) $\left(\mathrm{kg} / \mathrm{m}^{2}\right)$ was calculated from weight and height measurements taken at recruitment. Data on binge drinking (pattern of alcohol consumption), frequency, and type of alcohol consumption (beer, wine, spirits) was reported in the questionnaire along with weekly intensity (drinking units) of consumption for each type of alcoholic beverage. The reported glasses of wine, bottles of beer, and shots of spirits were converted to alcohol drinking units following National Health Service guidelines (National Health Service 2018). Regular alcohol drinkers were those individuals who consumed at least one unit of alcohol (including beer, wine, and spirits) per week during a year. Nonregular drinkers were those who did not report consuming weekly alcoholic beverages. Current drinkers were individuals who had consumed alcoholic beverages in the past year. Binge drinkers were those individuals who reported having had six or more alcoholic beverages, including beer, wine, and spirits, in a single session during the last year before interview. Current active smokers were those individuals who reported smoking. Ex-smokers were those who reported having smoked in the past, while non-smokers were individuals who reported that they never ever smoked.

\section{Blood processing and biochemical tests}

Levels of hs-CRP, HbAlc, lipid profile, liver function tests, and renal profile were measured on morning fasting blood samples. Research subjects were instructed to abstain from food, smoking, and alcohol consumption for $12 \mathrm{~h}$ before blood collection to minimize the acute effect of these factors on blood parameters. HbA1c levels were measured on EDTA whole blood using the Bio-Rad Variant II analyser (Bio-Rad Laboratories $\mathrm{GmbH}$, Germany). The lipid profile tests (total cholesterol, HDL cholesterol, triglyceride) were assayed in serum samples on the Roche/Hitachi cobas c311 system (Roche Diagnostics GmbH, Germany). LDL cholesterol was calculated using the Friedewald calculation except when triglyceride levels exceeded $4.52 \mathrm{mmol} / \mathrm{l}$, where the direct LDL cholesterol was assayed. Total bilirubin, aspartate aminotransferase (AST), alkaline phosphatase (ALP), alanine aminotransferase (ALT), gamma-glutamyltransferase (GGT), creatinine, urea, electrolytes (sodium, potassium, chloride, calcium), and uric acid were measured in serum samples on the Roche/Hitachi cobas ${ }^{\circledR}$ c311 system (Roche Diagnositcs 
$\mathrm{GmbH}$, Germany). Measurements of hs-CRP were obtained from serum samples on the Immulite 2000 immunoassay system (Siemens, USA). The normal reference ranges of the biochemical parameters to assess renal and liver function are those recommended by Roche Diagnostics. To assess renal function, the estimated glomerular filtration rate (eGFR) was computed using the Modified Diet Renal Disease (MDRD) formula (National Kidney Disease Education Program no date).

\section{Descriptive statistics and statistical analysis}

The effect of pattern, intensity, and frequency of alcohol consumption and the combined effect of smoking and alcohol consumption on levels of hs-CRP and lipid profile was determined using median levels and interquartile ranges in controls, separately for men and women. The mean age in the different categories was also determined. Results presented here are for male controls only, since the number of female controls in certain categories was small. The effect of alcohol on the lipid profile was also calculated in non-statin users and non-diabetics, to exclude any effects of statins and diabetes. Since the same trends were observed, the overall results are presented here. The Mann-Whitney test was used to compare medians between groups. A $p$ value of less than 0.1 was arbitrarily chosen to indicate significance. The Chi squared test was used to assess differences in the frequency of alcohol consumption between regular drinkers who are current smokers vs regular drinkers who are non-smokers. The risk of MI associated with the different frequency, pattern, type and intensity of alcohol consumption and with the combined effect of alcohol consumption and smoking was investigated. The relative risk of MI was calculated overall, and separately for men and women. Similar odds ratios (ORs) were observed for both genders, and so the overall ORs are presented here. Since the risk of MI and lipid profile parameters associated with ex-smoking depend on the years from smoking cessation (Attard et al. 2017), the effect of regular alcohol consumption on the lipid profile amongst ex-smokers could not be investigated, as upon stratification by regular drinking and years from smoking cessation the number of individuals in certain categories was too small. Thus, ex-smokers where excluded from the analysis of the effect of drinking and smoking on the lipid profile and hs-CRP levels. ORs were adjusted for age (Age OR), gender, smoking, reported hypertension, hypercholesterolemia, diabetes, and BMI (AdjOR). Diabetes and hypercholesterolemia were defined using both self-reported data from the questionnaire and measurements of $\mathrm{HbAlc}$ (using the $\geq 6.5 \%$ cut-off to define diabetes) and total cholesterol (using the $\geq 5.0 \mathrm{mmol} / \mathrm{l}$ cut-off to define hypercholesterolemia) respectively. The $95 \%$ confidence interval was calculated from the logistic regression model. All statistical analyses were performed using SPSS version 21.

\section{Results}

Characteristics of the MAMI Study cases and population controls are shown in Table 1 (Attard et al. 2017). Cardiovascular risk factors were more prevalent in cases compared with controls. A higher percentage of controls reported consuming regular alcoholic beverages compared to cases $(67 \%$ vs $59 \%, p$ value $<0.01)$.

\section{Frequency of alcohol consumption and risk of MI}

Regular alcohol consumption protected against MI [AdjOR $0.6(95 \%$ CI $0.4-0.9)$ ], in both young and elderly [ $<60$ years — AdjOR 0.6 (95\% CI 0.3-1.0); $\geq 60$ years - AdjOR 0.6 (95\% CI 0.3-0.9)]. This protective effect was also observed following restriction of the analysis to current drinkers, compared to the non-drinkers (Table 2a). The effect was independent of the frequency of consumption, with an AdjOR of 0.5 observed for both daily drinkers and for those who consume alcohol once a month or less (Table $2 b$ ).

\section{The effect of drinking pattern, intensity, and type of alcohol on the risk of $\mathrm{MI}$}

Daily binge drinking was a strong risk factor of MI [AdjOR 5.0 (95\% CI 1.6-15.0)], relative to regular drinkers who do not binge drink. Binge drinking was not a risk factor of $\mathrm{MI}$ if it occurred weekly, monthly, or less often than once a month (Table 3). Similar ORs were observed even after adjusting

Table 1 Characteristics of the MAMI study participants

\begin{tabular}{lll}
\hline & $\begin{array}{l}\text { Cases with MI': } \\
n=394\end{array}$ & $\begin{array}{l}\text { Controls: } \\
n=465\end{array}$ \\
\hline Men, $n(\%)$ & $316(80.2)$ & $327(70.3)$ \\
Age (years), mean (range) & $59(30-75)$ & $55(20-77)$ \\
Regular alcohol drinkers ${ }^{\mathrm{b}}, n(\%)$ & $232(58.9)$ & $311(66.9)$ \\
Smokers, $n(\%)$ & $146(37.1)$ & $105(22.6)$ \\
Ex-smokers, $n(\%)$ & $145(36.8)$ & $161(34.6)$ \\
Reported diabetes, $n(\%)$ & $110(28.2)$ & $53(11.9)$ \\
Reported hypertension, $n(\%)$ & $184(47.2)$ & $160(35.6)$ \\
Reported hypercholesterolemia, $n(\%)$ & $179(47.0)$ & $160(36.9)$ \\
Overweight $\left(\mathrm{BMI} 25-30 \mathrm{~kg} / \mathrm{m}^{2}\right)^{\mathrm{c}}, n(\%)$ & $136(41.7)$ & $197(42.6)$ \\
Obese $\left(\mathrm{BMI}>30 \mathrm{~kg} / \mathrm{m}^{2}\right)^{\mathrm{c}}, n(\%)$ & $149(45.7)$ & $173(37.4)$ \\
\hline
\end{tabular}

$B M I$ body mass index, MAMI Maltese Acute Myocardial Infarction, $M I$ myocardial infarction

${ }^{\text {a }}$ A total of 423 cases gave their consent to participating in the study, however, 29 cases did not complete their admission questionnaire, so questionnaire data about them is missing

${ }^{\mathrm{b}}$ Regular alcohol drinkers were defined as research subjects who consumed at least one unit of alcoholic beverage, including beer, wine, and spirits, per week in a year

${ }^{\mathrm{c}} \mathrm{BMI}$ cut-offs were as defined by WHO 
Table 2 Risk of MI due to (a) current drinking and (b) different frequency of alcohol consumption, during the last year before interview

\begin{tabular}{lllll}
\hline & Cases $(n=394)$ & Controls $(n=465)$ & Age OR (95\%CI) & AdjOR (95\% CI) \\
\hline $\begin{array}{llll}\text { (a) Current drinking } \\
\quad \text { Current drinkers }\end{array}$ & $287(72.8)$ & $402(86.5)$ & $0.5(0.3-0.7)$ & $0.4(0.3-0.6)$ \\
$\quad$ Non-drinkers & $107(27.2)$ & $63(13.5)$ & & 1.0 \\
(b) Frequency of alcohol consumption & & & & \\
Daily & $64(16.2)$ & $81(17.4)$ & $0.5(0.3-0.7)$ & $0.5(0.3-0.8)$ \\
4-6/week & $18(4.6)$ & $21(4.5)$ & $0.6(0.3-1.1)$ & $0.3(0.1-0.8)$ \\
2-3/week & $54(13.7)$ & $66(14.2)$ & $0.6(0.3-0.9)$ & $0.3(0.2-0.6)$ \\
2-4/month & $67(17.0)$ & $129(27.7)$ & $0.3(0.2-0.5)$ & $0.3(0.2-0.5)$ \\
Once a month or less often & $84(21.3)$ & $105(22.6)$ & $0.5(0.3-0.8)$ & $0.5(0.3-0.8)$ \\
Non-drinkers & $107(27.2)$ & $63(13.5)$ & 1.0 & 1.0 \\
\hline
\end{tabular}

ORs were adjusted for age [Age OR $(95 \% \mathrm{CI})]$ and for age, gender, diabetes, hypercholesterolemia, reported hypertension, smoking, and BMI [AdjOR $(95 \% \mathrm{CI})]$

95\% CI - 95\% confidence interval

for the type of alcohol consumed. Liver function tests and renal profile were assessed, and the increased risk of MI associated with daily binge drinking was not found to be due to liver or renal problems (data not shown).

Compared to individuals who do not consume regular alcoholic beverages, those who consumed between 1 and 10 drinking units of alcohol per week were protected against MI [AdjOR 0.5 (95\% CI 0.3-0.8)]. A consumption of more than 10 drinking units per week gave an AdjOR of 1.5 (95\% CI 0.9-2.5) (Table 4a). Different types of alcoholic beverages, including beer, wine, and spirits, exerted different effects on the risk of MI. Without taking into consideration the quantities, weekly wine consumption protected against MI [AdjOR 0.5 (95\% CI 0.3-0.9)], spirits gave an AdjOR of 0.6 (95\% CI 0.1-3.1), and beer increased the risk of MI by 3.5-fold (95\% CI 1.4-8.8) (Table 4b). These risks were modified by the drinking intensity. Individuals who consumed 19 units of wine per week were protected against MI [AdjOR
0.5 (95\% CI 0.3-0.8)] while the AdjOR for drinking $\geq 20$ units of wine weekly was 1.4 (95\% CI 0.5-3.7), compared with non-regular drinkers (Table 4c). High weekly consumption of beer ( $\geq 20$ weekly units of beer) was associated with a 4.3-fold (95\% CI 1.6-11.4) increased risk of MI, while 19 units of beer per week may convey a protective effect [AdjOR 0.5 (95\% CI 0.2-1.3)], relative to those who do not drink regularly (Table $4 \mathrm{c}$ ). The effect of increasing weekly consumption of spirits on the risk of MI could not be calculated due to the small number of individuals who reported weekly spirit consumption.

Amongst binge drinkers, cases tended to binge on beer while controls tended to binge on wine. Amongst cases, $44.4 \%$ of binge drinkers binged on beer, $11.1 \%$ on beer and spirits, $11.1 \%$ on beer and wine, $27.8 \%$ on beer, wine, and spirits and $5.6 \%$ binged on spirits only, whereas a total of $50.0 \%$ of binge drinking controls binged on wine and the other $50.0 \%$ binged on beer and wine (Fig. 1).

Table 3 Risk of MI due to binge drinking. Analysis was done only amongst individuals (males and females) who reported having consumed alcoholic beverages during the last year before the interview (non-drinkers, 107 cases and 63 controls, were excluded from this analysis)

\begin{tabular}{|c|c|c|c|c|c|}
\hline Frequency of binge drinking: & $\begin{array}{l}\text { Cases }^{\mathrm{a}} \\
(n=286)\end{array}$ & $\begin{array}{l}\text { Controls }^{\mathrm{b}} \\
(n=399)\end{array}$ & $\begin{array}{l}\text { Age OR } \\
(95 \% \mathrm{CI})\end{array}$ & $\begin{array}{l}\text { AdjOR } \\
(95 \% \text { CI })\end{array}$ & $\begin{array}{l}\text { AdjOR' } \\
(95 \% \mathrm{CI})\end{array}$ \\
\hline Daily & $19(6.6)$ & $5(1.3)$ & $6.5(2.3-17.8)$ & $5.0(1.6-15.0)$ & $3.3(1.0-11.1)$ \\
\hline Weekly & $39(13.6)$ & $34(8.5)$ & $2.0(1.2-3.3)$ & $1.1(0.6-2.1)$ & $1.0(0.6-1.9)$ \\
\hline Monthly & $21(7.3)$ & $24(6.0)$ & $1.7(0.9-3.3)$ & $1.0(0.4-2.2)$ & $1.0(0.5-2.2)$ \\
\hline Less often than once a month & $61(21.2)$ & $102(25.6)$ & $1.1(0.7-1.6)$ & $0.8(0.5-1.3)$ & $0.8(0.5-1.2)$ \\
\hline Regular drinkers who do not binge & $146(51.0)$ & $234(58.6)$ & 1.0 & 1.0 & 1.0 \\
\hline
\end{tabular}

ORs were adjusted for age [Age OR (95\% CI)], for age, gender, diabetes, hypercholesterolemia, reported hypertension, smoking, and BMI [AdjOR $(95 \% \mathrm{CI})$ ] and further for type of alcoholic beverage consumed [AdjOR' $(95 \% \mathrm{CI})$ ]

$95 \% \mathrm{CI}-95 \%$ confidence interval

a one case did not specify the frequency of binge drinking

${ }^{b}$ three controls did not specify the frequency of binge drinking 
Table 4 Risk of MI in relation to (a) intensity of weekly consumption, (b) type, and (c) number of weekly drinking units of specific types of alcoholic beverages, including wine, beer and spirits, compared with non- regular alcohol drinkers (individuals who did not report consuming alcoholic beverages on a weekly basis)

\begin{tabular}{|c|c|c|c|c|}
\hline Number of weekly alcoholic drinking units & $\operatorname{Cases}^{\mathrm{a}}(n=390)$ & Controls $(n=465)$ & Age OR $(95 \% \mathrm{CI})$ & AdjOR $(95 \% \mathrm{CI})$ \\
\hline$>10$ drinking units per week & $35(9.0)$ & $67(14.4)$ & $0.6(0.4-1.0)$ & $0.5(0.3-0.8)$ \\
\hline $1-10$ drinking units per week & $67(17.2)$ & $59(12.7)$ & $1.7(1.1-2.5)$ & $1.5(0.9-2.5)$ \\
\hline Non-regular drinkers & $288(73.8)$ & $348(74.8)$ & 1.0 & 1.0 \\
\hline \multicolumn{5}{|c|}{ (b) Type of alcoholic beverages consumed every week } \\
\hline Type of alcoholic beverage & $\operatorname{Cases}^{\mathrm{a}}(n=390)$ & Controls $(n=465)$ & Age OR $(95 \% \mathrm{CI})$ & AdjOR $(95 \% \mathrm{CI})$ \\
\hline Wine only & $28(7.2)$ & $65(14.0)$ & $0.5(0.3-0.8)$ & $0.5(0.3-0.9)$ \\
\hline Beer only & $26(6.7)$ & $7(1.5)$ & $4.7(2.0-11.2)$ & $3.5(1.4-8.8)$ \\
\hline Spirits only & $4(1.0)$ & $6(1.3)$ & $0.9(0.2-3.1)$ & $0.6(0.1-3.1)$ \\
\hline Beer + wine & $19(4.9)$ & $18(3.9)$ & $1.3(0.7-2.6)$ & $0.8(0.3-1.8)$ \\
\hline Spirits + wine & $7(1.8)$ & $5(1.1)$ & $1.5(0.5-4.8)$ & $1.3(0.3-6.1)$ \\
\hline Beer + spirits & $8(2.1)$ & $2(0.4)$ & $4.6(1.0-22.0)$ & $5.1(0.6-46.1)$ \\
\hline Beer + wine + spirits & $10(2.6)$ & $14(3.0)$ & $0.8(0.3-1.8)$ & $0.6(0.2-1.7)$ \\
\hline Non-regular drinkers & $288(73.8)$ & $348(74.8)$ & 1.0 & 1.0 \\
\hline \multicolumn{5}{|c|}{ (c) Weekly number of drinking units of different alcoholic beverages } \\
\hline \multicolumn{5}{|c|}{ Amongst individuals who consume wine per week } \\
\hline & Cases $(n=352)$ & Controls $(n=450)$ & Age OR $(95 \% \mathrm{CI})$ & $\operatorname{AdjOR}(95 \% \mathrm{CI})$ \\
\hline$\geq 20$ units/week & $12(3.4)$ & $11(2.4)$ & $1.1(0.5-2.6)$ & $1.4(0.5-3.7)$ \\
\hline 10-19 units/week & $14(4.0)$ & $20(4.4)$ & $0.8(0.4-1.6)$ & $0.6(0.2-1.6)$ \\
\hline $1-9$ units/week & $38(10.8)$ & $71(15.8)$ & $0.6(0.4-1.0)$ & $0.5(0.3-0.8)$ \\
\hline Non-regular drinkers & $288(81.8)$ & $348(77.3)$ & 1.0 & 1.0 \\
\hline \multicolumn{5}{|c|}{ Amongst individuals who consume beer per week } \\
\hline & Cases $(n=354)$ & Controls $(n=389)$ & Age OR $(95 \% \mathrm{CI})$ & AdjOR $(95 \% \mathrm{CI})$ \\
\hline$\geq 20$ units/week & $25(7.1)$ & $6(1.5)$ & $5.2(2.1-12.8)$ & $4.3(1.6-11.4)$ \\
\hline 10-19 units/week & $20(5.6)$ & $10(2.6)$ & $2.3(1.0-5.0)$ & $1.9(0.8-4.7)$ \\
\hline 1-9 units/week & $21(5.9)$ & $25(6.4)$ & $1.1(0.6-1.9)$ & $0.5(0.2-1.3)$ \\
\hline Non-regular drinkers & $288(81.4)$ & $348(89.5)$ & 1.0 & 1.0 \\
\hline \multicolumn{5}{|c|}{ Amongst individuals who consume spirits per week } \\
\hline & Cases $(n=318)$ & Controls $(n=375)$ & Age OR $(95 \% \mathrm{CI})$ & AdjOR $(95 \% \mathrm{CI})$ \\
\hline$\geq 20$ units/week & $6(1.9)$ & $1(0.3)$ & / & / \\
\hline 10-19 units/week & $4(1.3)$ & $6(1.6)$ & $0.8(0.2-2.8)$ & $0.4(0.1-1.8)$ \\
\hline 1-9 units/week & $20(6.3)$ & $20(5.3)$ & $1.1(0.6-2.1)$ & $0.9(0.4-2.2)$ \\
\hline Non-regular drinkers & $288(90.6)$ & $348(92.8)$ & 1.0 & 1.0 \\
\hline
\end{tabular}

ORs were adjusted for age [Age OR (95\% CI)] and for age, gender, diabetes, hypercholesterolemia, reported hypertension, smoking, and BMI [AdjOR $(95 \% \mathrm{CI})]$

95\% CI - 95\% confidence interval

${ }^{a}$ four cases who were regular alcohol drinkers did not specify the type and number of weekly alcohol consumption

\section{The modifying effect of alcohol on the risk of MI associated with smoking}

Regular alcohol drinking reduced risk of MI equally across smokers, non-smokers, and ex-smokers. Smokers who were non-regular alcohol drinkers had a 2.7-fold (95\% CI 1.4-5.3) increased risk of MI. This risk decreased to 1.9 -fold (95\% CI 1.1-3.4) in smokers who consumed regular alcoholic beverages. This reduction in risk of MI was also evident for ex-smokers [AdjOR 1.8 (95\% CI 0.9-3.4) who were non-regular drinkers vs AdjOR 1.0 (95\% CI 0.6-1.6), if they drank alcohol regularly], relative to non-smokers who were non-regular drinkers. An AdjOR of 0.7 (95\% CI 0.4-1.2) was observed amongst non-smokers who consumed alcohol regularly (Table 5). 
Fig. 1 Pie-chart showing the different types of beverages consumed by controls (layer 1) and cases (layer 2) who binge drink

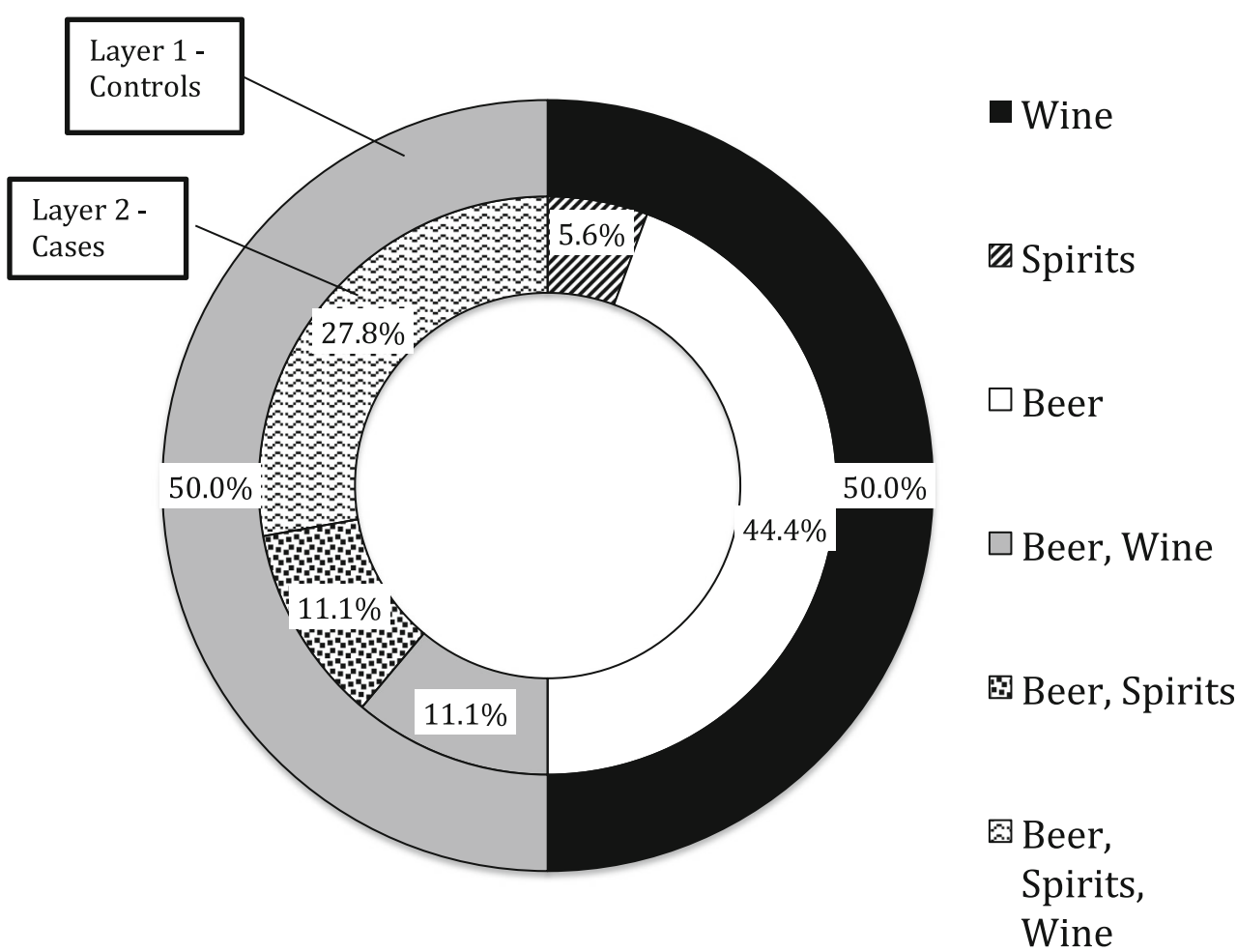

The impact of alcohol consumption on inflammation

Current drinkers had lower median hs-CRP levels than nondrinkers $(1.68 \mathrm{mg} / 1$ vs $2.47 \mathrm{mg} / \mathrm{l}, p$ value $<0.1)$ (Table $6 \mathrm{a}$ ). The lowest median hs-CRP was found amongst those who consume alcoholic beverages 4-6 times per week (Table 6b). Binge drinking weekly or less often had no effect on median hs-CRP levels compared to regular drinkers who did not binge drink (Supplement Table 1). The number of male controls who binged daily was too small to draw conclusions on trends in hs-CRP. The intensity of alcohol consumption (weekly drinking units) had no effect on median hs-
CRP levels (Table 6c). Amongst non-smokers, median hsCRP levels were similar in regular drinkers and in those that do not consume alcohol regularly (Table 7a). Amongst current smokers, regular drinking was associated with lower median levels of hs-CRP (1.96 mg/l vs $3.32 \mathrm{mg} / 1$ amongst those who do not drink regularly, $p$ value $<0.1$ ) (Table 8 a). Hs-CRP levels increase with age (Tang et al. 2018). Thus, given that smokers who were regular drinkers were younger than smokers who did not consume alcohol regularly, the analysis was restricted to individuals of 50 years and older to rule out any effects of age on median hs-CRP levels. Similar trends were observed (Tables $7 \mathrm{~b}$ and $8 \mathrm{~b}$ ).

Table 5 The combined effect of smoking and alcohol consumption on the risk of MI. The AdjOR for MI associated with regular drinking for each smoking category is also shown

\begin{tabular}{lllllll}
\hline \multicolumn{2}{l}{ Combined effect of smoking and alcohol consumption } & & & \\
\hline Smoking status & $\begin{array}{l}\text { Regular } \\
\text { drinkers }\end{array}$ & $\begin{array}{l}\text { Cases } \\
(n=394)\end{array}$ & $\begin{array}{l}\text { Controls } \\
(n=465)\end{array}$ & $\begin{array}{l}\text { Age OR } \\
(95 \% \text { CI })\end{array}$ & $\begin{array}{l}\text { AdjOR (95\% CI) } \\
\text { relative to non-smokers } \\
\text { and non-regular drinkers }\end{array}$ & $\begin{array}{l}\text { AdjOR (95\% CI) relative to } \\
\text { non-regular drinkers of } \\
\text { each smoking category }\end{array}$ \\
\hline Smokers & Yes & $89(22.6)$ & $75(16.1)$ & $2.2(1.4-3.5)$ & $1.9(1.1-3.4)$ & $0.6(0.3-1.2)$ \\
& No & $57(14.5)$ & $30(6.5)$ & $3.2(1.8-5.6)$ & $2.7(1.4-5.3)$ & 1.0 \\
Ex-smokers & Yes & $98(24.9)$ & $126(27.1)$ & $1.2(0.8-1.8)$ & $1.0(0.6-1.6)$ & $0.5(0.3-0.9)$ \\
& No & $47(11.9)$ & $35(7.5)$ & $2.0(1.2-3.5)$ & $1.8(0.9-3.4)$ & 1.0 \\
Non-smoker & Yes & $45(11.40$ & $110(23.7)$ & $0.6(0.4-1.1)$ & $0.7(0.4-1.2)$ & $0.7(0.4-1.2)$ \\
& No & $58(14.7)$ & $89(19.1)$ & 1.0 & 1.0 & 1.0
\end{tabular}

ORs were adjusted for age [Age OR (95\% CI)] and for age, gender, diabetes, hypercholesterolemia, reported hypertension, and BMI [AdjOR (95\% CI)] 95\% CI - 95\% confidence interval 

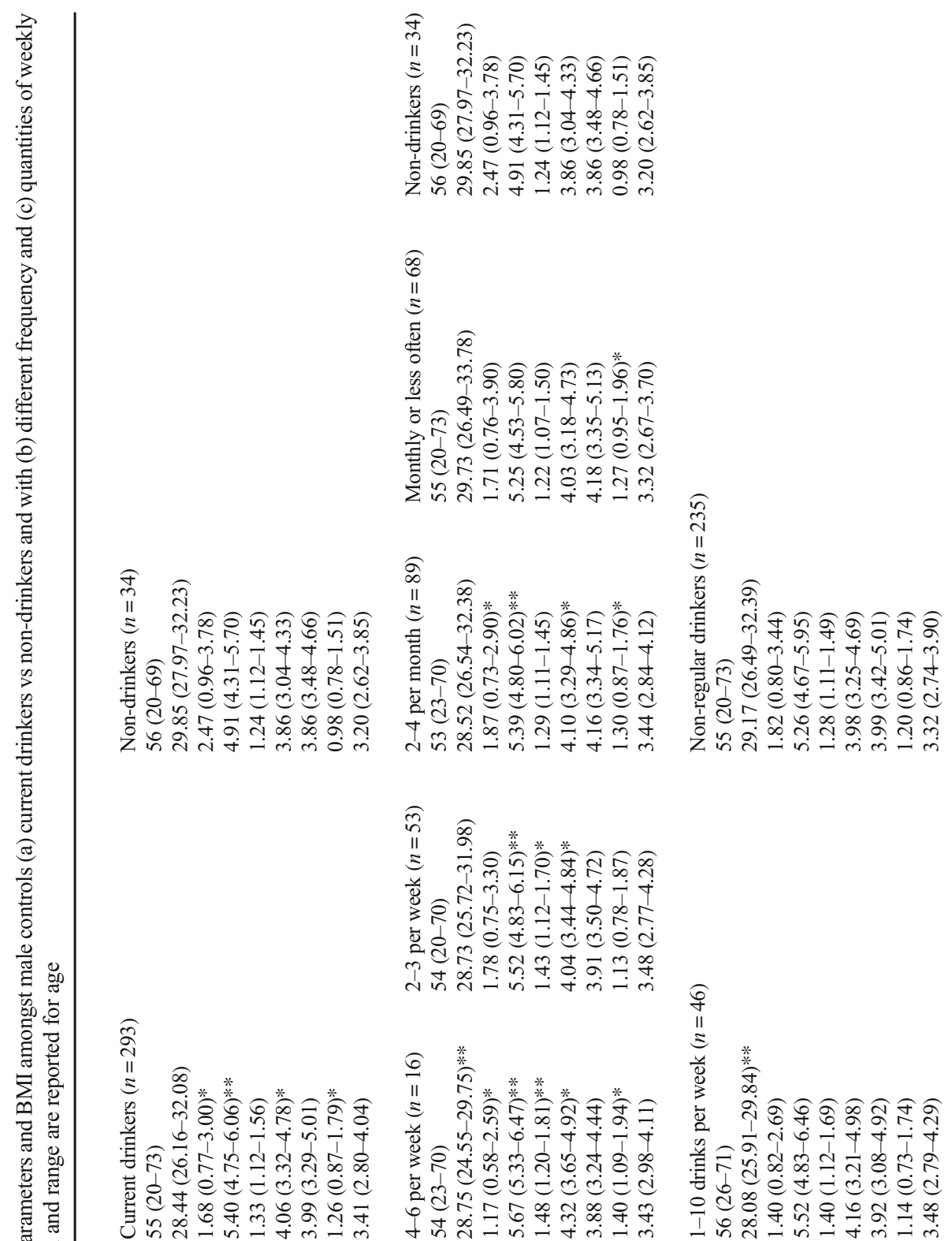

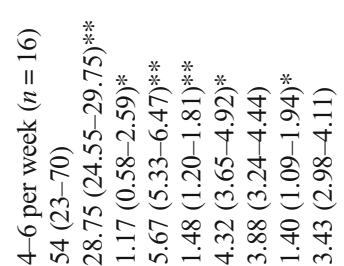

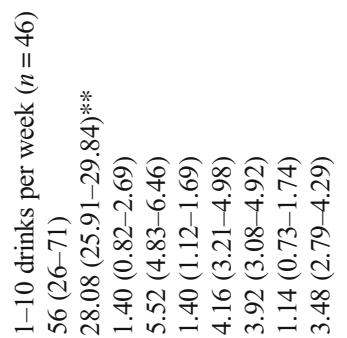

I nod

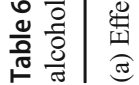
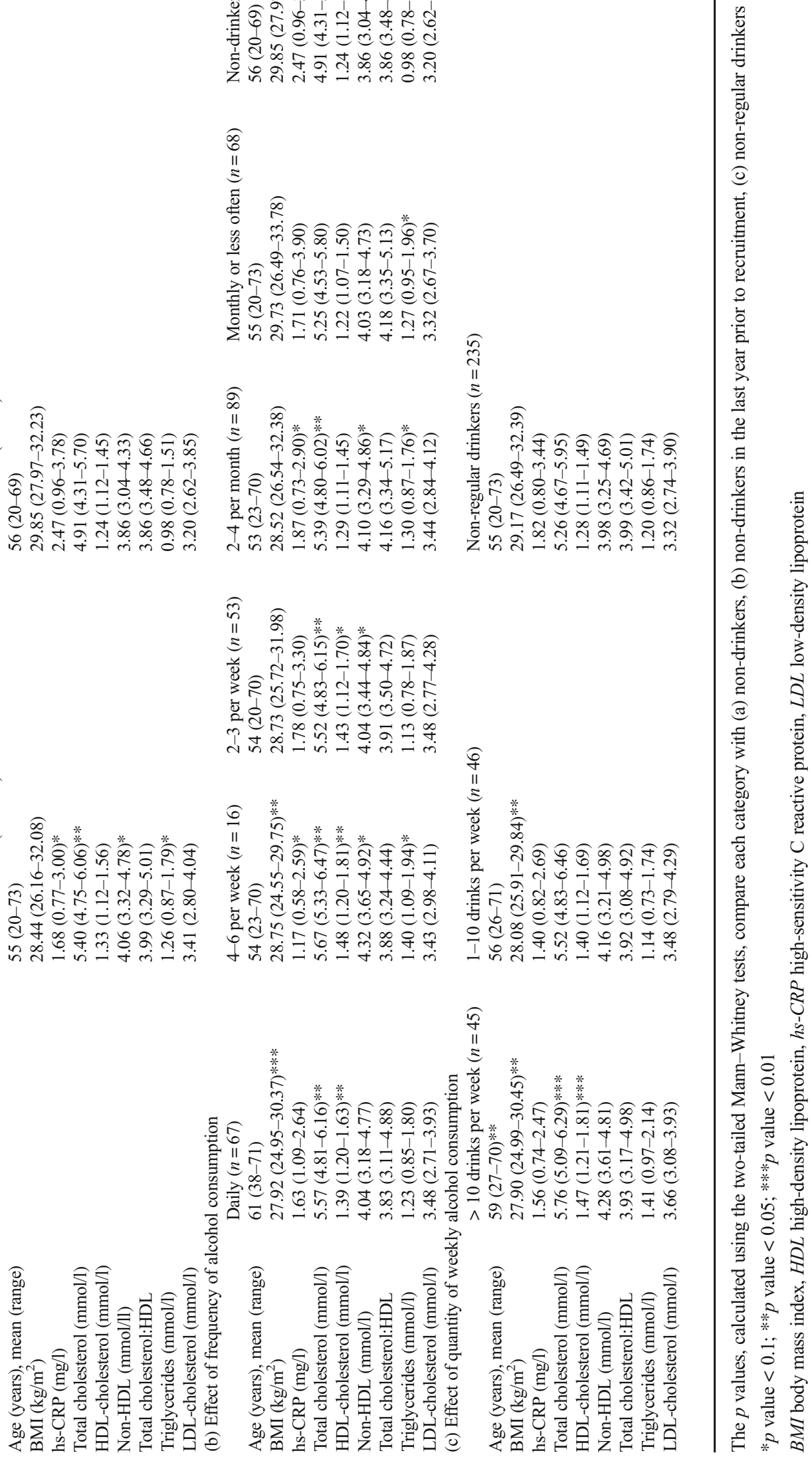
Table 7 Median levels and interquartile range of biochemical parameters and BMI amongst male controls with different smoking and alcohol consumption combinations (a) overall, and (b) limiting the analysis to $\geq 50$ years of age. Mean and range are reported for age

(a) Overall men

\begin{tabular}{|c|c|c|c|c|}
\hline & $\begin{array}{l}\text { Current drinkers who } \\
\text { smoke }(n=63)\end{array}$ & $\begin{array}{l}\text { Non-regular drinkers } \\
\quad \text { who smoke }(n=17)\end{array}$ & $\begin{array}{l}\text { Current drinkers } \\
\text { non-smokers }(n=71)\end{array}$ & $\begin{array}{l}\text { Non-regular drinkers } \\
\text { non-smokers }(n=45)\end{array}$ \\
\hline Age (years), mean (range) & $52(23-69)$ & $59(50-70)^{* *}$ & $53(20-70)$ & $52(20-69)$ \\
\hline BMI $\left(\mathrm{kg} / \mathrm{m}^{2}\right)$ & $27.92(24.53-32.04)$ & $29.31(27.10-31.70)$ & $28.19(25.67-32.10)$ & $28.14(25.96-32.39)$ \\
\hline hs-CRP (mg/l) & $1.96(0.72-4.23)$ & $3.32(1.66-5.11)^{* * *}$ & $1.61(0.68-3.00)$ & $1.09(0.73-2.48)$ \\
\hline Total cholesterol (mmol/l) & $5.32(4.73-5.91)^{*}$ & $5.8(5.16-6.59)^{* * *}$ & $5.36(4.97-6.03)^{* *}$ & $4.95(4.40-5.71)$ \\
\hline HDL-cholesterol (mmol/l) & $1.22(1.12-1.42)$ & $1.11(1.00-1.39)^{* * *}$ & $1.36(1.19-1.55)$ & $1.30(1.11-1.53)$ \\
\hline Non-HDL (mmol/l) & $3.98(3.30-4.81)^{* *}$ & $4.46(4.13-5.16)^{* * *}$ & $4.02(3.41-4.71) * *$ & $3.56(3.07-4.32)$ \\
\hline Total cholesterol:HDL & $4.23(3.34-5.05)^{*}$ & $5.13(4.35-6.27)^{* * *}$ & $3.98(3.22-4.72)$ & $3.64(3.17-4.45)$ \\
\hline Triglycerides (mmol/l) & $1.31(0.97-1.82)^{* * *}$ & $1.75(1.20-2.16)^{* * * *}$ & $1.16(0.79-1.57)$ & $0.86(0.74-1.43)$ \\
\hline \multirow{3}{*}{$\begin{array}{l}\text { LDL-cholesterol (mmol/l) } \\
\text { (b) In men } \geq 50 \text { years of ag }\end{array}$} & $3.21(2.76-3.92)$ & $3.67(3.30-4.38)^{* * * *}$ & $3.42(2.98-3.98) * *$ & $3.13(2.62-3.66)$ \\
\hline & & & & \\
\hline & $\begin{array}{l}\text { Current drinkers } \\
\text { who smoke }(n=42)\end{array}$ & $\begin{array}{l}\text { Non-regular drinkers } \\
\text { who smoke }(n=17)\end{array}$ & $\begin{array}{l}\text { Current drinkers } \\
\text { non-smokers }(n=49)\end{array}$ & $\begin{array}{l}\text { Non-regular drinkers } \\
\text { non-smokers }(n=32)\end{array}$ \\
\hline Age (years), mean (range) & $61(50-69) *$ & $59(50-70)$ & $60(50-70)$ & $58(50-69)$ \\
\hline BMI $\left(\mathrm{kg} / \mathrm{m}^{2}\right)$ & $28.87(24.53-32.19)$ & $29.31(27.10-31.70)$ & $28.81(26.10-32.04)$ & $28.41(26.43-32.78)$ \\
\hline hs-CRP (mg/l) & $2.19(1.05-4.56)$ & $3.32(1.66-5.11)^{* *}$ & $1.51(0.81-2.56)$ & $1.51(0.84-2.85)$ \\
\hline Total cholesterol (mmol/l) & $5.46(4.87-6.04)^{*}$ & $5.80(5.16-6.59)^{* *}$ & $5.48(5.00-6.24)^{* *}$ & $4.97(4.40-5.77)$ \\
\hline HDL-cholesterol (mmol/l) & $1.33(1.16-1.56)$ & $1.11(1.00-1.39)$ & $1.36(1.09-1.56)$ & $1.25(1.03-1.53)$ \\
\hline Non-HDL (mmol/l) & $4.07(3.29-4.85)$ & $4.46(4.13-5.16)^{* * *}$ & $4.06(3.68-5.07)^{*}$ & $3.57(3.07-4.32)$ \\
\hline Total cholesterol:HDL & $3.98(3.29-5.02)$ & $5.13(4.35-6.27)^{* * *}$ & $4.10(3.19-5.13)$ & $3.71(3.16-4.64)$ \\
\hline Triglycerides (mmol/l) & $1.54(1.07-2.04)^{* *}$ & $1.75(1.20-2.16)^{* * *}$ & $1.21(0.79-1.63)$ & $1.12(0.77-1.70)$ \\
\hline LDL-cholesterol (mmol/l) & $3.41(2.78-3.92)$ & $3.67(3.30-4.38)^{* *}$ & $3.50(3.15-4.21)^{* *}$ & $3.10(2.56-3.66)$ \\
\hline
\end{tabular}

The $p$ values, calculated according to the two-tailed Mann-Whitney tests, compare each category with non-smokers who are non-regular drinkers $* p$ value $<0.1 ; * *$ value $<0.05 ; * * p$ value $<0.01$

BMI, body mass index; HDL, high-density lipoprotein; hs-CRP, high-sensitivity C reactive protein; LDL, low-density lipoprotein

\section{The impact of alcohol consumption on the lipid profile}

Current alcohol drinkers had higher median total cholesterol, non-HDL, and triglycerides levels than the non-drinkers (Table 6a). Taking the frequency of consumption into account revealed that current drinkers had higher median levels of total cholesterol and non-HDL cholesterol compared with nondrinkers if consumption was more frequent than monthly, and higher HDL-cholesterol if consumption was more frequent than 2-3 times per week (Table 6b). Those who consumed alcoholic beverages 4-6 times per week or more had a lower BMI than non-drinkers. No significant difference in mean age was present between the different categories. No changes in lipid profile parameters were evident with binge drinking compared with regular drinkers who do not binge drink (Supplementary Table 1). The number of daily binge drinkers was too small to analyse median levels. Median BMI decreased and median total cholesterol and HDLcholesterol increased with increasing weekly alcohol drinking units, reaching statistical significance for individuals drinking
$>10$ drinking units per week compared with those who do not consume alcohol regularly (Table 6c). All lipid profile parameters were higher amongst non-smokers who were current drinkers compared with non-smokers who are non-regular drinkers, reaching a statistically significant difference for total cholesterol, non-HDL-cholesterol and LDL-cholesterol (Table 7a). These remained significant when analysis was restricted to individuals of 50 years or older (Table 7b). Current smokers who were non-regular drinkers had significantly higher median levels of total cholesterol, non-HDL-cholesterol, total cholesterol:HDL-cholesterol ratio, triglycerides, and LDL-cholesterol, and lower HDL-cholesterol levels than nonsmokers who were non-regular drinkers (Table 7a). Since the mean age of current smokers who were non-regular drinkers was significantly higher than that of non-smoking non-regular drinkers (59 years vs 52 years, $p$ value $<0.05$ ), data was restricted to individuals of 50 years or older (Table $7 \mathrm{~b}$ ). The observed differences in the lipid profile were still present upon restriction (Table 7b). Current smokers who were also current drinkers had significantly lower median levels of total-cholesterol, non-HDL-cholesterol, total cholesterol:HDL- 
Table 8 Median levels and interquartile range of biochemical parameters and BMI amongst male controls who smoke and are regular drinkers versus smokers who are non-regular drinkers, (a) overall and (b) limiting the analysis to $\geq 50$ years of age. Mean and range are reported for age

(a) Overall men

Age (years), mean (range)

BMI $\left(\mathrm{kg} / \mathrm{m}^{2}\right)$

hs-CRP (mg/l)

Total cholesterol $(\mathrm{mmol} / \mathrm{l})$

HDL-cholesterol (mmol/l)

Non-HDL (mmol/l)

Total cholesterol:HDL

Triglycerides (mmol/l)

LDL-cholesterol (mmol/l)

(b) In men $\geq 50$ years of age

Age (years), mean (range)

BMI $\left(\mathrm{kg} / \mathrm{m}^{2}\right)$

hs-CRP (mg/l)

Total cholesterol (mmol/l)

HDL-cholesterol (mmol/l)

Non-HDL (mmol/l)

Total cholesterol:HDL

Triglycerides (mmol/l)

LDL-cholesterol (mmol/l)
Current drinkers who smoke $(n=63)$

52 (23-69)

$27.92(24.53-32.04)$

$1.96(0.72-4.23)^{*}$

$5.32(4.73-5.91)^{*}$

$1.22(1.12-1.42)^{*}$

$3.98(3.30-4.81)^{* *}$

$4.23(3.34-5.05)^{* *}$

$1.31(0.97-1.82)^{*}$

$3.21(2.76-3.92)^{*}$

Current drinkers who smoke $(n=42)$

$61(50-69)$

$28.87(24.53-32.19)$

$2.19(1.05-4.56)$

$5.46(4.87-6.04)$

$1.33(1.16-1.56)^{* *}$

$4.07(3.29-4.85)^{*}$

$3.98(3.29-5.02)^{* *}$

$1.54(1.07-2.04)$

$3.41(2.78-3.92)^{*}$
Non-regular drinkers who smoke $(n=17)$

59 (50-70)

$29.31(27.10-31.70)$

$3.32(1.66-5.11)$

$5.80(5.16-6.59)$

$1.11(1.00-1.39)$

$4.46(4.13-5.16)$

$5.13(4.35-6.27)$

$1.75(1.20-2.16)$

$3.67(3.30-4.38)$

Non-regular drinkers who smoke $(n=17)$ 59 (50-70)

$29.31(27.10-31.70)$

$3.32(1.66-5.11)$

$5.80(5.16-6.59)$

$1.11(1.00-1.39)$

$4.46(4.13-5.16)$

$5.13(4.35-6.27)$

$1.75(1.20-2.16)$

$3.67(3.30-4.38)$

The $p$ values, calculated according to the two-tailed Mann-Whitney tests, compare smokers who are regular drinkers vs. smokers who are non-regular drinkers

${ }^{*} p$ value $<0.1 ; * * p$ value $<0.05 ; * * *$ value $<0.01$

$B M I$ body mass index, $H D L$ high-density lipoprotein, $h s-C R P$ high-sensitivity $\mathrm{C}$ reactive protein, $L D L$ low-density lipoprotein

cholesterol ratio, triglycerides, LDL-cholestero, and higher HDL-cholesterol levels than current smokers who were nonregular drinkers (Table 8). These trends remained after restricting the data to those older than 50 years (Table 8b). Whilst there were improvements in the lipid profile amongst smokers who were also current drinkers compared to smokers who were non-regular drinkers, current drinking was associated with a worse lipid profile in non-smokers, despite the fact that smokers tended to drink alcohol more frequently (Supplement Table 2). All the trends remained even after excluding statin users from the analysis as well as after excluding diabetics.

\section{Discussion}

Low-to-moderate alcohol consumption protects against MI, despite it being associated with higher median levels of total-cholesterol, non-HDL-cholesterol, and triglycerides. At least part of this protective effect could be due to its antiinflammatory properties. Its effect on the risk of MI depends greatly on the pattern, frequency, and intensity of alcohol consumption, and the type of alcoholic beverage. Daily binge drinking exerted a strong deleterious effect on the risk of MI. A consumption of 1-10 drinking units per week was protective, while a weekly consumption of more than 10 drinking units increased risk of MI. An altered lipid profile was found in those who consumed more than 10 drinking units per week. Whereas weekly consumption of wine was protective, weekly consumption of beer was associated with a 3.5-fold increased risk of MI. Alcohol decreased the risk of MI irrespective of smoking status. Current smokers who were also current alcohol drinkers had significantly lower levels of hs-CRP, total cholesterol, non-HDL-cholesterol, total cholesterol:HDL-cholesterol ratio, triglycerides, and LDL-cholesterol, and higher levels of HDL-cholesterol when compared with smokers who were non-regular drinkers. On the other hand amongst nonsmokers, current drinkers had higher total cholesterol, nonHDL-cholesterol, and LDL-cholesterol compared with the non-regular drinkers.

The protective effect of low-to-moderate alcohol consumption and the deleterious effect of daily binge drinking on risk of myocardial infarction were confirmed in this study (Romelsjo et al. 2012; Ronksley et al. 2011; Leong et al. 
2014; Biyik and Ergene 2007). The protective effect of alcohol consumption is already evident for those drinking once a month or less often. Binge drinking counteracted the protective effect of alcohol, with daily binge drinking increasing risk 3.3-fold. Inflammation, known to mediate all stages of atherosclerosis and ultimately the risk of MI (Libby et al. 2002), was lower amongst current alcohol drinkers than among nondrinkers, as indicated by lower levels of hs-CRP. This indicates that at least part of the protective effect of moderate alcohol consumption on the risk of MI may be mediated by its anti-inflammatory effects. These findings are in accord with observations from other studies (De Lorgeril and Salen 2004; Kesteloot 2004). In addition, others have also demonstrated the positive effects of low-to-moderate alcohol consumption on vascular function, antioxidant capacity, and the coagulation system (Lindberg and Amsterdam 2008). These effects have been proposed as the mechanisms through which alcohol is associated with a reduction in the risk of cardiovascular disease (Friedman and Kimball 1986; Muntwyler et al. 1998). High alcohol consumption and binge drinking have been associated with negative effects on health, including the development of alcohol dependence syndrome, liver cirrhosis, accidents, and increased mortality (Estruch et al. 1993; Brien et al. 2011; Ronksley et al. 2011). The deleterious effects of higher alcohol intake may be explained, at least in part, by alcohol-induced complications on organs such as the liver, and by confounding effects of other behavioural factors associated with alcohol consumption. These include diet, physical exercise (Breslow et al. 2010; French et al. 2009), and smoking (Grucza and Bierut 2006). Our data has been adjusted for smoking status.

Although studies on alcohol and risk of MI are numerous, few were designed to investigate the effect of pattern, type, and intensity of alcoholic beverages consumed on the risk of MI. Those who drank only beer had a 3.5-fold increased risk of MI while those who drank only wine were protected with an AdjOR of 0.5 (95\% CI 0.3-0.9). Similarly to previous observations (Cleophas 1999; Schroder et al. 2007), small doses of wine and beer were found to offer the same protective effect on the risk of MI in this study. It is known that polyphenols found in wine and beer exhibit antioxidant (Vinson et al. 2003), anti-inflammatory (Palmieri et al. 2011), hypotensive (Bhatt et al. 2011), and anti-coagulant properites (Crescente et al. 2009). However, while wine remained protective with increasing weekly doses up to a consumption of 10-19 units, concordant with findings reported by others (Schroder et al. 2007), beer conveyed a deleterious effect with increasing consumption from 10 or more units per week, reaching a 4.3-fold increased risk of MI amongst individuals consuming more than 19 weekly units of beer. This opposing effect between high consumption of wine and beer may be related to their different polyphenolic content (Arran et al. 2012). Amongst the complex mechanisms that may be contributing to the protective effect of wine on the risk of MI is the decrease in fasting insulin and glucose levels, attributed to either the ethanol and/or polyphenolic content (Ruf 2003; Estruch and Lamuela-Raventos 2010; Schrieks et al. 2015). Additionally, while both wine and beer lower postprandial glycaemia, the effect is stronger for wine than for beer (Brand-Miller et al. 2007). Beer also has a very high glycaemic index that is frequently underestimated (Sinkko et al. 2012). Type of alcohol could also be a factor influencing the effects of binge drinking, since most of the cases binged on beer while controls binged on wine alone or wine and beer.

Findings with regard to the benefits of beer on the cardiovascular system are conflicting, ranging from no effect (Salonen et al. 1983; Bobak et al. 2000), lower risk, and no dose-response effect (Di Castelnuovo et al. 2002) to a Jshaped relationship for increasing beer consumption (Costanzo et al. 2011). These conflicting findings are possibly due to the amount of ethanol present in different types of beer, with the different carbohydrate/ethanol content affecting the alcohol-induced reactive hypoglycaemia upon consumption (Joffe et al. 1982), and also due to failure to account for the different types of alcoholic beverages consumed concurrently. In this study, the deleterious effect of beer consumption on the risk of MI was lower amongst individuals who consumed both wine and beer. These findings suggest that the non-alcoholic component of different types of beverages and not the alcohol content alone affect the risk of MI. Thus it is important to take into account the type of alcoholic beverage and not only consider the grams of alcohol in beverages. Only a small number of individuals reported consuming spirits on a weekly basis, and so conclusions with regard to its effect on the risk of MI could not be drawn from this study. Others have suggested that high spirit intake increases risk of MI (Schroder et al. 2007).

In this study, current drinking was associated with higher median levels of total cholesterol, non-HDL-cholesterol, and triglycerides. These effects were only evident in those who consumed alcohol 2-4 times per month or more often. Alcohol consumption was associated with a rise in median HDL-cholesterol levels if consumption was 2-3 times per week or more often. The effect of alcohol on lipid metabolism is complex. Ethanol perturbs both hepatic (You and Arteel 2019) and extra-hepatic lipid metabolism, where the acetate formed from alcohol metabolism leads to formation of acetylCoA used in cholesterol synthesis (Zakhari 2013). This explains the observed rise in total cholesterol with increasing frequency of alcohol consumption. The rise in HDLcholesterol amongst alcohol drinkers is likely to be due to an increase in the transport rate of HDL apolipoproteins ApoA-I and ApoA-II (De Oliveira e Silva et al. 2000), as well as to the increased activity of lipoprotein lipase (LPL) (Nishiwaki et al. 1994). Others have already reported a positive association between alcohol intake and fasting triglyceride levels, which 
is dependent on the amount of alcohol consumed and not on the pattern of consumption, as regular and binge drinking had the same effect (Van de Wiel 2011). Part of this effect is due to a decrease in the capacity for triglyceride clearance by alcohol consumption (Zemankova et al. 2015). These effects on the lipid profile are independent of BMI, as BMI decreased with increasing frequency of alcohol consumption. Results with regard to the association between BMI and alcohol consumption are conflicting, possibly due to failure to take into account smoking status and type of alcohol consumed (Breslow and Smothers 2005; Arif and Rohrer 2005; Vadstrup et al. 2005).

Apart for the frequency of consumption, the intensity also influenced the lipid profile parameters. Higher median levels of total cholesterol and HDL-cholesterol were observed in individuals who consumed more than 10 weekly drinking units. Binge drinking had no effect on the lipid profile. The different effects on the lipid profile posed by the frequency and intensity of alcohol consumption observed in this study offer an explanation for some of the conflicting results present in the literature, where the effect of moderate alcohol intake on the lipid profile has been reported to range from reduction in triglycerides and increased HDL-cholesterol ( $\mathrm{Vu}$ et al. 2016), to increase in both triglycerides and HDL-cholesterol (Ruidavets et al. 2002), and to increase in triglycerides and lower HDL-cholesterol (Park and Kim 2012).

We have previously reported the effect of smoking on lipid profile and inflammation (Attard et al. 2017). Alcohol and smoking often occur together (Grucza and Bierut 2006), possibly since smoking may result in a greater tendency to consume alcohol, at least in mice (Benjamin et al. 2013). Research on the effect of interactions between smoking and alcohol consumption on the risk of MI is limited (LussierCacan et al. 2002). In the MAMI Study, alcohol decreased risk of MI, independent of smoking status. This is similar to what has been observed in other studies (Tavani et al. 2001). Smoking status modified the effects of alcohol on the lipid profile. While amongst non-smokers, current drinking was associated with a worse lipid profile (higher median levels of total cholesterol, non-HDL cholesterol, and LDL-cholesterol), amongst smokers, current drinking improved the lipid profile (lower median levels of total cholesterol, non-HDLcholesterol, total cholesterol:HDL-cholesterol ratio, triglycerides and LDL-cholesterol and higher median levels of HDLcholesterol) and decreased hs-CRP levels, thus overcoming part of the inflammatory effect of smoking. A decrease in total cholesterol and LDL-cholesterol and higher HDL-cholesterol levels have previously been reported amongst smokers who consume alcoholic beverages compared to smokers who are non-drinkers (Wakabayashi 2008). In the MAMI Study, the difference in the lipid profile parameters between current alcohol drinkers who smoke and non-smokers was independent of the frequency of alcohol consumption, as despite tending to have a higher frequency of alcohol consumption (associated with an abnormal lipid profile), alcohol use in smokers still showed an improved lipid profile compared with nonsmokers.

The protective effect of alcohol consumption on the risk of MI amongst non-smokers can be mediated via other mechanisms including differences in the apolipoprotein composition, effects on vascular function and on antioxidative, anticoagulant (Lindberg and Amsterdam 2008), and /or hypotensive properties (Bhatt et al. 2011). In addition, it is known that alcohol drinkers have a differential methylation pattern associated with the expression of a number of genes involved in the immune response pathway (Liu et al. 2018). Thus, epigenetic changes may also be involved in the complex mechanisms through which alcohol exerts its effects.

Despite these findings, it should be pointed out that alcohol consumption may exert deleterious effects on general health (GBD 2016 Alcohol Collaborators 2018), particularly due to its addictive properties (Mitchell et al. 2012), and may have an opposite impact on other diseases and conditions (Pandeya et al. 2009). Heavy drinking is known to increase coronary heart disease mortality (Hart et al. 2010). Alcohol is a leading risk factor for global disease burden. In 2016, tuberculosis, road injuries, and self-harm were the three leading causes of alcoholattributable deaths in the population aged between 15 and 49 years, and cancer accounted for a large proportion of alcohol-attributable deaths in those aged 50 years or older. The effect of alcohol on health is influenced by the intensity of consumption and drinking pattern, with the risk of all-cause mortality and of cancer increasing with increasing level of alcohol consumption (GBD 2016 Alcohol Collaborators 2018).

A limitation of this study is that no information was collected on the type of wine consumed, and so different effects of red and white wine on the risk of MI cannot be investigated. We could not measure the individual effects of beer, wine, and spirit consumption on the lipid profile and inflammation, since upon stratification the number of research subjects in certain groups was small. Alcohol units were calculated based on data reported by participants; thus, the volume of a bottle of beer, glass of wine, and shot of spirit is approximate. Differences in the observations amongst non-smokers in this study and in that of Wakabayashi, who reported no difference in total cholesterol, lower LDL-cholesterol, and higher HDL-cholesterol in non-smokers who consumed alcohol compared with non-smokers non-drinkers (Wakabayashi 2008), may be due to the use of a different reference category (nondrinkers vs non-regular drinkers as used in this study) as well as other differences including the type of beverages, pattern of consumption, and population differences, such as genetic differences in alcohol-metabolizing enzymes (Harada et al. 1981). The effects of alcohol can be 
modified if taken with food. Wine is more frequently accompanied by food than beer in the population under study. This was not assessed in this study, so any modifying effects of accompanying food intake on the risk of MI associated with alcohol cannot be excluded.

Findings presented here strongly indicate that the risk of MI may be influenced by factors which may convey a different effect when found in combination than when present alone. These results corroborate findings of other authors and highlight the need for alcohol consumption to be taken into account when determining the cardiovascular risk score, along with other conventional risk factors of MI. Smoking influences the relationship between alcohol consumption, lipid profile, inflammation, and risk of MI. Given the high incidence of smoking and alcohol consumption, further studies on the modifying effect of alcohol are warranted. The antiinflammatory effect of alcohol explains at least part of its protective effect against risk of MI. The pattern, intensity, and type of alcoholic beverages consumed affect risk of MI and not just the alcohol content; thus, studies should take these factors into account besides the amount of alcohol consumed. These observations highlight the complexity of MI and the need to analyse the risk of MI in the context of different combinations of environmental backgrounds.

Acknowledgements The following departments at Mater Dei Hospital, Msida, Malta are also acknowledged:

The Departments of Cardiology and Medicine were involved in recruitment of cases, the ECG department for conducting ECGs on all research subjects, and Department of Pathology for phlebotomy, biochemical and hematological testing.

The Laboratory of Molecular Genetics carried out isoelectric focusing of haemoglobins.

The CCU ward, outpatients, ECG department and laboratory at Gozo General Hospital, Victoria, Gozo were involved in the recruitment of Gozitan research subjects. Mr. Adrian Pleven and Ms. Anna Lisa Sciortino are acknowledged for overseeing biochemical tests carried out on the Immulite 2000.

Authors' contributions All authors reviewed and provided edits and comments on manuscript drafts. In addition, authors had the following responsibilities: S.B.W. designed the MAMI Study and was the principal investigator; R.A. was involved in research subject recruitment, laboratory testing, sample processing, and all data analyses, and was responsible for writing this manuscript; P.D. was involved in research subject recruitment, clinically assessed all cases to verify they fit in the recruitment criteria, and was responsible for waist and hip measurements; C.D. was responsible for overall study design and for overseeing data analysis; K.C. was responsible for ethical issues, clinical aspects, and logistics in recruitment; R.F. was involved in recruitment, selection of testing methodology, running of the project, and scientific advice. S.B.W. had full access to all the data, oversaw all phases of the study, and takes responsibility for the integrity of the data, accuracy of the data analysis, and contents of this article.

Funding information This work was carried out as part of the MAMI Study, a collaboration between the University of Malta and the Malta Department of Health. It was supported by national funding through the R\&I program 2008 administered by the Malta Council for Science and
Technology (MCST). The research work disclosed in this publication is also partially funded by the Malta Government Scholarships Scheme (MGSS). The funding sources played no role in the study design, recruitment of research subjects, analysis and interpretation of the data, nor in the writing and submission of this paper for publication.

Data availability The datasets used and/or analysed during the current study are available from the corresponding author on reasonable request.

\section{Compliance with ethical standards}

Ethics approval and consent to participate This study was approved by the research ethics committee of the University of Malta (Reference number MD 32/2010). Written informed consent was obtained from all research subjects.

Role of the funding source The funding sources played no role in the study design, recruitment of research subjects, analysis and interpretation of the data, or the writing and submission of this paper for publication.

Consent for publication Not applicable.

Competing interests The authors declare that they have no competing interests.

Open Access This article is licensed under a Creative Commons Attribution 4.0 International License, which permits use, sharing, adaptation, distribution and reproduction in any medium or format, as long as you give appropriate credit to the original author(s) and the source, provide a link to the Creative Commons licence, and indicate if changes were made. The images or other third party material in this article are included in the article's Creative Commons licence, unless indicated otherwise in a credit line to the material. If material is not included in the article's Creative Commons licence and your intended use is not permitted by statutory regulation or exceeds the permitted use, you will need to obtain permission directly from the copyright holder. To view a copy of this licence, visit http://creativecommons.org/licenses/by/4.0/.

\section{References}

Alpert JS, Thygesen K, Antman E, Bassand JP (2000) Myocardial infarction redefined - a consensus document of the joint European Society of Cardiology/American College of Cardiology Committee for the redefinition of myocardial infarction. J Am Coll Cardiol 36:959-969

Arif AA, Rohrer JE (2005) Patterns of alcohol drinking and its association with obesity: data from the Third National Health and Nutrition Examination Survey, 1988-1994. BMC Public Health 5:26

Arran S, Chiva-Blanch G, Valderas-Martinez P, Medina-Remon A, LamuelaRaventos RM, Estruch R (2012) Wine, beer, alcohol and polyphenols on cardiovascular disease and cancer. Nutrients 4:759-781

Attard R, Dingli P, Doggen CJM, Cassar K, Farrugia R, Bezzina Wettinger S (2017) The impact of passive and active smoking on inflammation, lipid profile and the risk of myocardial infarction. Open Heart 4:e000620. https://doi.org/10.1136/openhrt-2017000620

Benjamin E, Burns BS, Proctor WR (2013) Tobacco smoke exposure greatly increases alcohol consumption in C57BL/6 mice. Alcohol Clin Exp Res 37:364-372

Bhatt SR, Lokhandwala MF, Banday AA (2011) Resveratrol prevents endothelial nitric oxide synthase uncoupling and attenuates 
development of hypertension in spontaneously hypertensive rats. Eur J Pharmacol 667:258-264

Biyik I, Ergene O (2007) Alcohol and acute myocardial infarction. J Int Med Res 35:46-51

Bobak M, Shodova Z, Marmot M (2000) Effect of beer drinking on risk of myocardial infarction: population based case-control study. BMJ 320:1378-1379

Brand-Miller JC, Eatama K, Middlemiss C, Bare M, Liu V, Atkinson F, Petocz P (2007) Effect of alcoholic beverages on postprandial glycemia and insulineamia in lean, young, healthy adults. Am J Nutr 85:1545-1551

Breslow RA, Smothers BA (2005) Drinking patterns and body mass index in never smokers: National Health Interview Survey, 19972001. Am J Epidemiol 161:368-376

Breslow RA, Guenther PM, Juan W, Graubard BI (2010) Alcoholic beverage consumption, nutrient intakes, and diet quality in the US adult population, 1999-2006. J Am Diet Assoc 110:551-562

Brien SE, Ronksley PE, Turner BJ, Mukamal KJ, Ghali WA (2011) Effect of alcohol consumption on biological markers associated with risk of coronary heart disease: systematic review and meta-analysis of interventional studies. BMJ 342:d636

Cleophas TJ (1999) Wine, beer and spirits and the risk of myocardial infarction: a systematic review. Biomed Pharmacother 53:417-423

Costanzo S, Di Castelnuovo A, Donati MB, Iacoviello L, de Gaetano G (2011) Wine, beer or spirit drinking in relation to fatal and non-fatal cardiovascular events: a meta-analysis. Eur J Epidemiol 26:833-850

Crescente M, Jessen G, Momi S, Holtje HD, Gresele P, Cerletti C, de Gaetano G (2009) Interactions of gallic acid, resveratrol, quercetin and aspirin at the platelet cyclooxygenase-1 leve. Functional and modelling studies. Thromb Haemost 102:336-346

De Lorgeril M, Salen P (2004) Is alcohol anti-inflammatory in the context of coronary heart disease? Heart 90:355-357

De Oliveira e Silva ER, Foster D, McGee Harper M, Seidman CE, Smith JD, Brinton EA (2000) Transport rate of apolipoproteins A-I and AII. Circulation 102:2347-2352

Di Castelnuovo A, Rotondo S, Iacoviello L, Donati MB, de Featano G (2002) Meta-analysis of wine and beer consumption in relation to vascular risk. Circulation 105:2836-2844

Estruch R, Nicolas JM, Villegas E, Junque A, Urbano-Marquez A (1993) Relationship between ethanol-related diseases and nutritional status in chronically alcoholic men. Alcohol Alcohol 28:543-550

Estruch R, Lamuela-Raventos RM (2010) Alcohol, wine and cardiovascular disease, two sides of the same coin. Intern Emerg Med 5:277-279

French MT, Popovici I, Maclean JC (2009) Do alcohol consumers exercise more? Findings form a national survey. Am J Health Promot 24:2-10

Friedman LA, Kimball AW (1986) Coronary heart disease mortality and alcohol consumption in Framingham. Am J Epidemiol 124:481-489

GBD 2016 Alcohol Collaborators (2018) Alcohol use and burden for 195 countries and territories, 1990-2016: a systematic analysis for the Global Burden of Disease Study 2016. Lancet 392:1015-1035

Grucza RA, Bierut LJ (2006) Co-occurring risk factors for alcohol dependence and habitual smoking. Update on findings from the Collaborative Study on the Genetics of Alcoholism. Alcohol Res Health 29:172-178

Harada S, Agarwal DP, Goedde HW (1981) Aldehyde dehyfrogenase deficiency as cause of facial flushing reaction to alcohol in Japanese. Lancet 2:982

Hart CL, Smith GD, Gruer L, Watt GCM (2010) The combined effect of smoking tobacco and drinking alcohol on cause-specific mortality: a 30 year cohort study. BMC Public Health 10:789. https://doi.org/10. 1186/1471-2458-10-789

Joffe BI, Shires R, Lamprey JM, Baker SG, Seftel HC (1982) Effect of drinking bottled beer on plasma insulin and glucose responses in normal subjects. S Afr Med J 62:95-97
Keichl S, Willeit J, Rungger G, Egger G, Oberlhollenzer F, Bonora E (1998) Alcohol consumption and atherosclerosis: what is the relation? Prospective results from the Bruneck Study. Stroke 29:900-907

Kesteloot H (2004) Alcohol intake and markers of inflammation. Eur Heart J 25:2075-2076

Leong DP, Smyth A, Teo KK, McKee M et al (2014) Patterns of alcohol consumption and myocardial infarction risk: observations from 52 countries in the INTERHEART case-control study. Circulation 113: 390-398

Libby P, Ridker PM, Maseri A (2002) Inflammation and atherosclerosis. Circulation 105:1135-1143

Lindberg ML, Amsterdam EA (2008) Alcohol, wine, and cardiovascular health. Clin Cardiol 31:347-351

Liu C, Marioni RE, Hedman AK et al (2018) A DNA methylation biomarker of alcohol consumption. Mol Psychiatry 23:422-433

Lussier-Cacan S, Bolduc A, Xhignesse M, Niyonsenga T, Sing CF (2002) Impact of alcohol intake on measures of lipid metabolism depends on context defined by gender, body mass index, cigarette smoking and Apolipoprotein E genotype. Arterioscler Thromb Vasc Biol 22: 824-831

McKee M, Britton A (1998) The positive relationship between alcohol and heart disease in eastern Europe: potential physiological mechanisms. J R Soc Med 91:402-407

Mitchell JM, O’Neil JP, Janabi M, Marks SM, Jagust WJ, Fields HL (2012) Alcohol consumption induces endogenous opioid release in the human orbitofrontal cortex and nucleus accumbens. Sci Transl Med 4:116ra6

Muntwyler J, Hennekens CH, Buring JE, Gaziano JM (1998) Mortality and light to moderate alcohol consumption after myocardial infarction. Lancet 352:1882-1885

National Kidney Disease Education Program (no date). Adapted from http://nkdep.nih.gov/lab-evaluation/gfr/estimating.shtml\#mdrdstudy-equation. Accessed 14 December 2014

National Health Service (2018). https://www.nhs.uk/live-well/alcoholsupport/calculating-alcohol-units/. Accessed 17 May 2019

Nishiwaki M et al (1994) Effects of alcohol on lipoprotein lipase, hepatic lipase, cholesteryl ester transfer protein, and lecithin:cholesterol acyltransferase in high-density lipoprotein cholesterol elevation. Atherosclerosis 111:99-109

Palmieri D, Pane B, Barisione C, Spinella G, Garibaldi S, Ghigliotti G, Brunelli C, Fulcheri E, Palombo D (2011) Resveratrol counteracts systemic and local inflammation involved in early abdominal aortic aneurysm development. J Surg Res 171:e237-e246

Pandeya N, Williams G, Green AC, Webb PM, Whiteman DC, Australian Cancer Study (2009) Alcohol consumption and the risks of adenocarcinoma and squamous cell carcinoma of the esophagus. Gastroenterology 136:1215-1224

Park H, Kim K (2012) Association of alcohol consumption with lipid profile in hypertensive men. Alcohol Alcohol 47:282-287

Romelsjo A, Allebeck P, Andreasson S, Leifman A (2012) Alcohol, mortality and cardiovascular events in a 35 year follow-up of a nationwide representative cohort of 50,000 Swedish conscripts up to age 55. Alcohol 47:322-327

Ronksley PE, Brein SE, Turner BJ, Mukamal KJ, Ghali WA (2011) Association of alcohol consumption with selected cardiovascular disease outcomes: a systematic review and meta-analysis.BMJ 342:d671

Ruf JC (2003) Overview of epidemiological studies on wine, health and mortality. Drugs Exp Clin Res 29:173-179

Ruidavets J, Ducimetiére P, Arveiler D, Amouyel P, Bingham A, Wagner A, Cottel D, Perret B, Ferrieres J (2002) Types of alcoholic beverages and blood lipids in a French population. J Epidemiol Community Health 56:24-28

Salonen JT, Puska P, Nissinen A (1983) Intake of sprits and beer and risk of myocardial infarction and death - a longitudinal study in eastern Finland. J Chronic Dis 36:533-543 
Schrieks IC, Heil ALJ, Hendriks HFJ, Mukamal KJ, Beulens JWJ (2015) The effect of alcohol consumption on insulin sensitivity and glycemic status: a systematic review and meta-analysis of intervention studies. Diabetes Care 38:723-732

Schroder H, Masabeu A, Marti MJ et al (2007) Myocardial infarction and alcohol consumption: a population-based case-control study. Nutr Metab Cardiovasc Dis 17:609-615

Sinkko K, Leiviska J, Valsta LM (2012) Modifying effect of alcohol on the postprandial glucose and insulin responses in healthy subjects. Am J Clin Nutr 96:44-49

Tang Y, Liang P, Chen J, Fu S, Liu B, Feng M, Lin B, Lee B, Xu A, Lan HY (2018) The baseline levels and risk factors for high-sensitivity C-reactive protein in Chinese healthy population. Immun Ageing 15:21

Tavani A, Bertuzzi M, Negri E, Sorbara L, La Vecchia C (2001) Alcohol, smoking, coffee and risk of non-fatal acute myocardial infarction in Italy. Eur J Epidemiol 17:1131-1137

You M, Arteel GE (2019) Effect of ethanol on lipid metabolism. J Hepatol $70: 237-248$

Wakabayashi I (2008) Associations of alcohol drinking and cigarette smoking with serum lipid levels in healthy middle-aged men. Alcohol Alcohol 43:274-280

Vadstrup ES, Petersen L, Sørensen TIA, Grønbæk M (2005) Waist circumference in relation to history of amount and type of alcohol: results from the Copenhagen City Heart Study. Int J Obes 27:238-246

$\mathrm{Vu} \mathrm{KN}$, Ballantyne CM, Hoogeveen RC, Nambi V, Volcik KA, Boerwinkle E, Marrison AC (2016) Causal role of alcohol consumption in an improved lipid profile: the Atherosclerosis Risk in Communities (ARIC) study. PLoS One 11(2):e0148765. https:// doi.org/10.1371/journal.pone. 0148765

Van de Wiel A (2011) The effect of alcohol on postprandial and fasting triglycerides. Int J Vasc Med 2012:862504. https://doi.org/10.1155/ 2012/862504

Vinson JA, Mandarano M, Hirst M, Trevithick JR, Bose P (2003) Phenol antioxidant quantity and quality in foods: beers and the effect of two types of beer on an animal model of atherosclerosis. J Agric Food Chem 51:5528-5533

Zakhari S (2013) Alcohol metabolism and epigenetics changes. Alcohol Res 35:6-16

Zemankova K, Makoveichuk E, Vlasakova Z, Olivecrona G, Kovar J (2015) Acute alcohol consumption downregulated lipoprotein lipase activity in vivo. Metabolism 64:1592-1596

Prior presentation Part of this work was presented in a poster at the European Atherosclerosis Society Meeting, 2014, Madrid, Spain.

Publisher's note Springer Nature remains neutral with regard to jurisdictional claims in published maps and institutional affiliations. 